\title{
HPLC Characterization of Phytochemicals and Antioxidant Potential of Alnus nitida (Spach) Endl.
}

\author{
Javed Khan ${ }^{1}$, Abdul Majid ${ }^{1}$, Nausheen Nazir ${ }^{2, * \mathbb{D}}$, Mohammad Nisar ${ }^{3, *}$, Atif Ali Khan Khalil ${ }^{4}$ (D), \\ Muhammad Zahoor ${ }^{2}$ (D), Mohammad Ihsan ${ }^{3}$, Riaz Ullah ${ }^{5}$ D , Ahmed Bari ${ }^{6}(D)$ and Abdul Bari Shah ${ }^{7}$
}

1 Department of Botany, Hazara University Mansehra, Mansehra 18800, Khyber Pakhtunkhwa, Pakistan; javedwari@gmail.com (J.K.); abdulmajidhu@gmail.com (A.M.)

2 Department of Biochemistry, University of Malakand Chakdara, Dir Lower, Chakdara 18800, Khyber Pakhtunkhwa, Pakistan; zahoor@uom.edu.pk

3 Department of Botany, University of Malakand Chakdara, Dir Lower, Chakdara 18800, Khyber Pakhtunkhwa, Pakistan; ihsanbotanist@gmail.com

4 Department of Biological Sciences, National University of Medical Sciences, Rawalpindi 46000, Punjab, Pakistan; atif.khalil7799@gmail.com

5 Department of Pharmacognosy, College of Pharmacy, King Saud University, Riyadh 11451, Saudi Arabia; rullah@ksu.edu.sa

6 Department of Pharmaceutical Chemistry, College of Pharmacy, King Saud University, Riyadh 11451, Saudi Arabia; abari@ksu.edu.sa

7 Division of Applied Life Science (BK21 Plus), IALS, Gyeongsang National University, Jinju 52828, Korea; abs.uom28@gmail.com

* Correspondence: nausheen.nazir@uom.edu.pk (N.N.); nisarhu@gmail.com (M.N.)

Citation: Khan, J.; Majid, A.; Nazir, N.; Nisar, M.; Khan Khalil, A.A.; Zahoor, M.; Ihsan, M.; Ullah, R.; Bari, A.; Shah, A.B. HPLC Characterization of Phytochemicals and Antioxidant Potential of Alnus nitida (Spach) Endl. Horticulturae 2021, 7, 232. https:/ / doi.org/10.3390/horticulturae7080232

Academic Editor: Riccardo Motti

Received: 17 July 2021

Accepted: 5 August 2021

Published: 8 August 2021

Publisher's Note: MDPI stays neutral with regard to jurisdictional claims in published maps and institutional affiliations.

Copyright: (C) 2021 by the authors. Licensee MDPI, Basel, Switzerland. This article is an open access article distributed under the terms and conditions of the Creative Commons Attribution (CC BY) license (https:/ / creativecommons.org/licenses/by/ $4.0 /)$.
Abstract: Antioxidants isolated from plants have attracted the interest of clinicians and common people to be used for systemic uses rather than synthetic antioxidants because of their active role in maintaining human health with minimal side effects. Alnus nitida (Spach) Endl. is an important medicinal plant native to western Himalaya and is widely distributed throughout Pakistan. The present study evaluates the phytochemical composition of this plant using HPLC along with the total content of phenolics and flavonoids. The antioxidant activities were determined following the Brand William assay. The methanolic extract (Met. Ext) of leaves, stem bark, seeds, and roots of A. nitida were used to scavenge synthetic free radicals such as DPPH and ABTS. From HPLC fingerprinting of the $A$. nitida selected portion, six possible phytochemicals were confirmed. Among the identified phytochemicals, there are six compounds (malic acid, chlorogenic acid, epigallocatechin gallate, quercetin, ellagic acid and pyrogallol) in the leaves of $A$. nitida, three (epigallocatechin gallate, ellagic acid, and pyrogallol) in the stem bark, six in the seeds (malic acid, vitamin C, epigallocatechin gallate, quercetin, ellagic acid, and pyrogallol), and five (malic acid, epigallocatechin gallate, quercetin, and ellagic acid) in root. Comparatively, the highest antioxidant potentials were recorded for the leaves extract ( $\mathrm{IC}_{50}$ of 340 and $645 \mu \mathrm{g} / \mathrm{mL}$ against DPPH and ABTS, respectively). The percentages of inhibition were compared with the positive control ascorbic acid, which produced an $\mathrm{IC}_{50}$ value of $60 \mu \mathrm{g} / \mathrm{mL}$ each against the free radicals DPPH and ABTS. The highest phenolics (43.81 mg GAE/g sample) were found in the roots, while the highest flavonoid contents ( $53.25 \mathrm{mg}$ QE/g sample) were in the leaves. It was assumed that observed antioxidant potentials of the tested plant might be due to their phytochemicals confirmed through HPLC, and thus, this plant may be a valuable candidate in treating oxidative stress and related disorders. However, further investigations are needed to isolate responsible components in pure from. Furthermore, toxicological effects in in vivo animal models are also needed to confirm the results observed in this study.

Keywords: HPLC characterization; antioxidants; TPC; TFC; synthetic free radicals (DPPH and ABTS) 


\section{Introduction}

Traditionally, people gathered plant and animal resources for food, health care, and shelter. In developing countries, millions of people derive a substantial part of their daily needs and livelihood from animal and plant resources. There is high demand for wild species of plants due to interest in their medicinal properties [1]. Currently, the overexploitation of natural resources, particularly the wild species of plants, has attracted the attention of conservationists, and certain species are threatened to go extinct in the near future if their overuse is not controlled. In the modern world, medicinal plants are considered the backbone of pharmaceutical industries due to their valuable phytochemical constituents [2].

It is a common practice around the world, especially in third-world countries, to use plants as such or in the form of extracts, such as decoctions, infusions, or tinctures, for home remedies in curing many common diseases. Despite the tremendous advances in human medicines, the spread of infectious diseases caused by bacteria, fungi, viruses, and other parasites remains a serious threat to public health [3]. The plant kingdom is a valuable means of producing a wide range of natural antioxidants and health-beneficial phytochemicals. Phytochemicals have exhibited therapeutic properties such as antibacterial, antifungal, antidiabetic, antioxidant, anticancer, etc., and are considerably effective as compared to their synthetic counterparts. The antioxidants are vital compounds present in plants needed for healthy life in humans, as a number of reactive oxygen species are constantly produced during normal oxidation, which are scavenged by antioxidant enzymes; plant antioxidants help these enzymes in scavenging them [4].

Alnus nitida (Spach) Endl. (Figure 1) is the member of family Betulaceae, commonly known as Sharol in Urdu and called Geiray in Pashto. About 30 species of this Alnus, in form of shrubs and trees, are distributed worldwide. In Pakistan, it is found in Swat, Dir, and Murree. It is a deciduous woody tree reaching $20 \mathrm{~m}$ in height or taller. It can grow in shady places and prefers wet soil. The species has wide distribution; however, it is most commonly found along the rivers banks. It also grows in the temperate parts of the Himalayas. It usually occurs at an elevation range between 1000 to $3500 \mathrm{~m}$ above sea level [5]. A. nitida has been reported as an ethnobotanically significant plant. Apart from its wild populations, the species of this family are also cultivated in agroforestry. Different parts of this plant are used by local communities in northern Pakistan. Traditionally, the stem bark of $A$. nitida has been used as a medicine to treat swelling, injury, and pain. Reported studies indicate its uses in treating health complications such as cancer, hypertension, anthelmintic, reproductive, and CNS disorders. The stem bark of $A$. nitida is also used by the local community to treat inflammation-related complications. The therapeutic effect may be due to the presence of polyphenols and other components such as sterols and terpenoids that alleviate the inflammation and act as pain-inducing mediators [5]. The inhabitants of Swat and Malakand, where this plant is abundantly found, use it as an anti-inflammatory agent [5]. For bone fractures, the residents of these areas mix the stem bark or root of A. nitida with Urtica dioica, Rumex nepalensis, and Zingiber officinale and apply the paste externally [5]. In a published study, A. nitida extract showed anti-inflammatory and cytotoxic activity due to the presence of phytochemicals detected by GCMS [6]. The methanol extract and its fractions obtained from the stem bark of $A$. nitida showed the presence of terpenoids, saponins, and coumarins, phenols and flavonoids. Its total phenols (TPC) and total flavonoids (TFC) content are high and have powerful antioxidant and hepatoprotective activity against CCl4-induced hepatotoxicity recorded in the rat model [7]. Sajid et al. [7] have reported the active constituents such as gallic acid, catechin, and rutin in A. nitida extract ethyl acetate and aqueous fraction using HPLC-DAD analysis. It is also used for the treatment of diarrhea, common fever, hemorrhages, and burn injuries [8]. Reported studies have revealed the presence of bioactive compounds in A. nitida such as tannins, carbohydrates, starch, flavonoids, resin, glycosides, and cardiac glycosides that might be responsible for biological activities including antibacterial, antifungal, phytotoxicity, insecticidal, cytotoxic, and leishmanicidal activities [9]. 
(A)

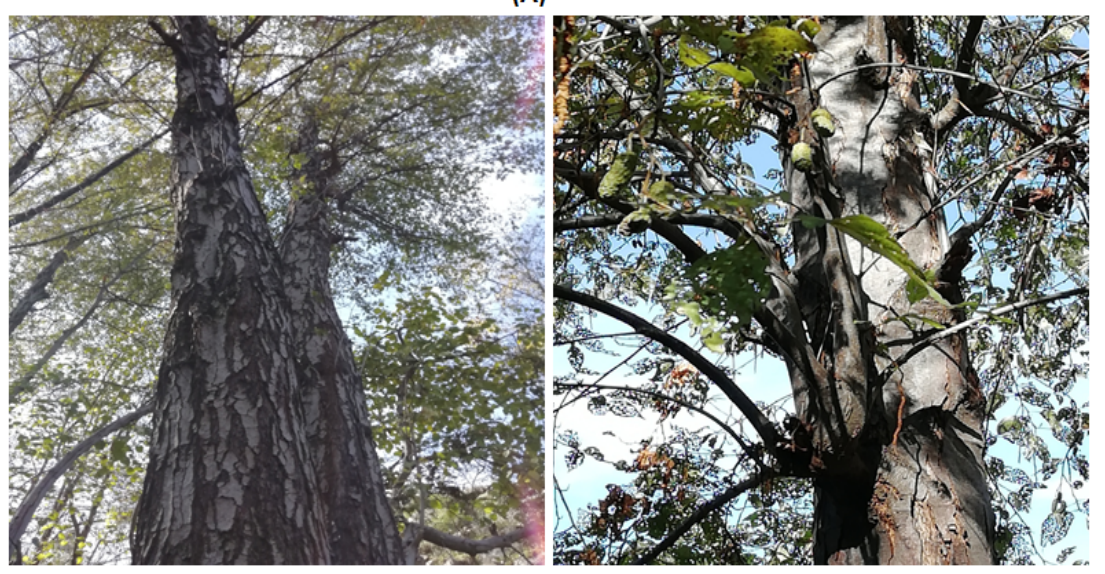

(B)

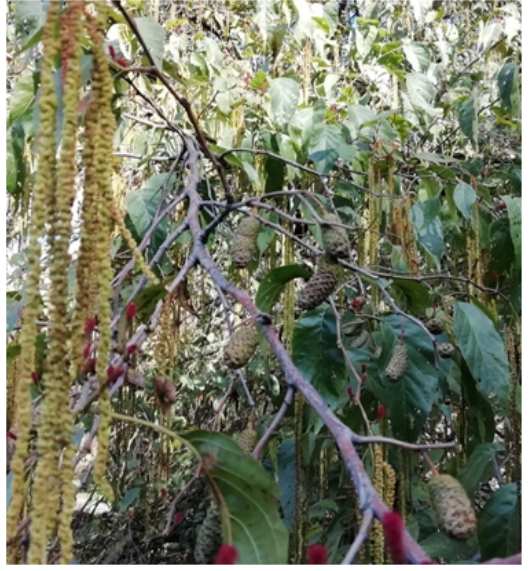

(C)

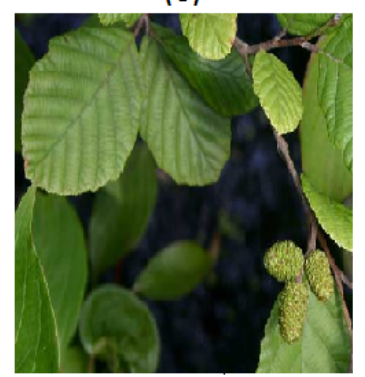

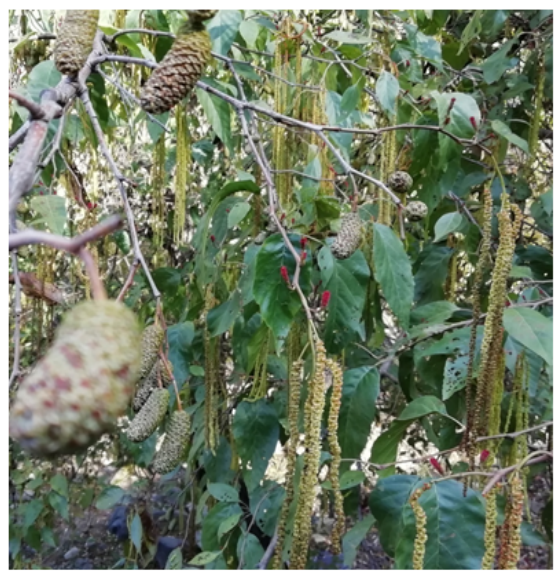

(D)

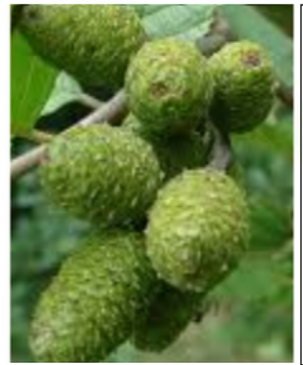

(E)

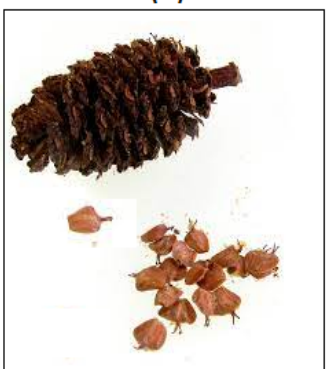

Figure 1. Alnus nitida (Spach) Endl. plant and its various parts. (A) Woody tree with dark red bark, (B) A. nitida tree bearing catkins and cones, (C) A. nitida leaves, (D) A. nitida cones, and (E) mature cone with seeds.

Species of the genus Alnus are also documented for their traditional medicinal values. A mixture of leaves of $A$. jorullensis and branches of Polylepis racemosa are used to treat uterine infections, uterine cancer, and rheumatism [10]. The bark of A. glutinosa is used to treat swelling, inflammation, and rheumatism [11]. Alnus species contain diarylheptanoids, a group of natural products with a 1,7-diphenylheptane structure that give these plants various therapeutic properties such as anti-inflammatory, anti-tumor and antioxidant properties. About 400 diarylheptanoids have been isolated from different Alnus species that have shown pharmacological activities such as anti-inflammatory, anti-influenza, cytotoxic, and hepatoprotective effects [12]. The crude methanolic extract from $A$. nitida stem bark and leaf and its derived fractions has shown considerable antioxidant, anti-cancer, and hepatoprotective activity $[7,13]$.

Throughout Pakistan, $A$. nitida is the most popular plant with natural antioxidants and has attracted much interest because of its immense health benefits. Considering the 
medicinal value of $A$. nitida, this study aims to determine the total phenol/flavonoid content, HPLC profiling, and antioxidant potential of different part of A. nitida (bark, leaf, seed, and root) growing in Malakand Division, Khyber Pakhtunkhwa, Pakistan. The methanolic extract of $A$. nitida displayed a significant antioxidant activity, which might be due to phytochemicals confirmed through HPLC analysis.

\section{Material and Methods}

\subsection{Chemical Reagents}

The antioxidant standards, ascorbic acid, chlorogenic acid, ellagic acid, epigallocatechin gallate, malic acid, pyrogallol, and quercetin were obtained from Sigma-Aldrich, St. Quentin Fallavier, France. $\mathrm{K}_{2} \mathrm{SO}_{4}$ (potassium sulfate); $\mathrm{Na}_{2} \mathrm{CO}_{3}$ (sodium carbonate); $\mathrm{NaNO}_{3}$ (sodium nitrate); 2, 2-Diphenyle-1 Picryl-hydrazyle (DPPH); Folin-ciocalteu reagent; 2, 2-Azinobis [3-Ethylbenzthiazoline]-6-sulfonic acid (ABTS); methanol, $\mathrm{ACl}$ (Aluminum chloride); and $\mathrm{NaOH}$ (Sodium hydroxide) were purchased from Sigma-Aldrich, Darmstadt, Germany. Analytical grads solvents were used in the study and obtained from SigmaAldrich, Germany (HPLC analysis).

\subsection{Collection of Plant Material}

Plant material (stem bark, leaves, seeds and roots) was collected from healthy A. nitida trees at various locations in the Malakand Division, Khyber Pakhtunkhwa, Pakistan in 20192020. The plant samples were deposited were deposited in the Botanical Garden Herbarium, University of Malakand, Pakistan, with the voucher number of B.G.H-UOM-185.

\subsection{Extract Preparation}

The extraction procedure is carried out according to the previously reported assay [14]. Approximately $2.5 \mathrm{~kg}$ of powdered plant parts (bark, leaves, seeds and roots) were soaked in $15 \mathrm{~L}$ of methanol $(80 \%)$ and distilled water $(20 \%)$ for 14 days. The sample was filtered through muslin and Whatman filter paper. The filtrate was converted into a semi-solid substance on a rotary evaporator (Schwabach: 4000, Heidolph Laborota, Schwabach, Germany) at $40{ }^{\circ} \mathrm{C}$ under reduced pressure. Finally the semisolid mass was changed into then solidified mass ( $1.5 \mathrm{~g}$ yield) in open air.

\subsection{Estimation of Total Phenolic Content (TPC)}

About $100 \mu \mathrm{L}$ of the diluted extract was taken in a test tube, to which distilled water $(500 \mu \mathrm{L})$ and Folinciocalteu reagent (FCR) $(100 \mu \mathrm{L})$ were added, mixed well and left to stand for $6 \mathrm{~min}$ [15]. After that $7 \%$ sodium carbonate $(1000 \mu \mathrm{L})$ and another $500 \mu \mathrm{L}$ of distilled water were then added to the tube, the mixture was then shaken at room temperature and incubated for $90 \mathrm{~min}$. Finally, measure the absorbance at $760 \mathrm{~nm}$ with an ultraviolet spectrophotometer. The acid curve was also drawn. The total phenolic content in the samples was calculated from the standard gallic acid calibration curve and stated as $\mathrm{mg}$ gallic acid equivalent per gram (mg GAE/g) dry extract.

\subsection{Estimation of Total Flavonoids Content (TFC)}

Kim et al. assay [16] was used to evaluate the total flavonoid content in which already prepared extract $(100 \mu \mathrm{L})$ solutions were mixed with distilled water $(500 \mu \mathrm{L})$. Then $5 \%$ sodium nitrate $(100 \mu \mathrm{L}), 10 \%$ aluminum chloride $(150 \mu \mathrm{L})$, and $1 \mathrm{M}$ sodium hydroxide $(200 \mu \mathrm{L})$ was added to the extract solution and kept for $5 \mathrm{~min}$. Finally, the absorbance at $510 \mathrm{~nm}$ was measured with a UV spectrophotometer. Quercetin standard, for which a calibration curve was created, was used to calculate the total content of flavonoids as $\mathrm{mg}$ of quercetin equivalent $(\mathrm{mg} \mathrm{QE} / \mathrm{g}$ ) per gram of extract [9]. The results are recorded in triplicate. 


\subsection{Extracts Preparation for HPLC Characterization}

For HPLC characterization and quantification, the reported method was followed [17]. Approximately $1 \mathrm{~g}$ of powdered sample was mixed with methanol and water $(20 \mathrm{~mL} ; 1: 1)$, heated for $1 \mathrm{~h}$ at $70{ }^{\circ} \mathrm{C}$ in a water bath and finally centrifuged for $10 \mathrm{~min}$ at $4000 \mathrm{rpm}$. After filtration via PTFE filter, the sample $(2 \mathrm{~mL})$ was put into HPLC vials. The Agilent 1260 Infinity HPLC system with basic parts including a UV detector, quaternary pump, degasser, and autosampler was used to identify phenolic compounds. Separation of phytochemicals was achieved via Agilent Zorbax Eclipse XDBC18 column with the gradients system comprising and solvent A gradient system (methanol: acetic acid: deionized water, 100:20:180, v/v volume) and solvent B (methanol: Acetic acid: deionized water, 900:20:80, v/v). The column is kept at $25^{\circ} \mathrm{C}$. Different gradient procedures were evaluated. The most effective gradient programs start at $100{ }^{\circ} \mathrm{C} \mathrm{A}$ at $0 \mathrm{~min}, 85^{\circ} \mathrm{C} \mathrm{A}$ at $5 \mathrm{~min}, 50 \% \mathrm{~A}$ at $20 \mathrm{~min}, 30 \% \mathrm{~A}$ at $25 \mathrm{~min}$, and $100 \% \mathrm{~B}$ from 30 to $40 \mathrm{~min}$. The injection volume is set to $10 \mu \mathrm{L}$. The UV detector was set to $280 \mathrm{~nm}$ for the analysis of phenolic compounds. Phenolic compounds were identified by comparing their retention times and UV spectra of the unknown sample with those of the available standards, while quantification was done by determining the percentage of peak area using the following one-point calibration formula:

$$
C x=\frac{A x \times C s\left(\frac{\mu g}{m L}\right) \times V(m L)}{A s \times \text { Sample wt }(g m)}
$$

where $\mathrm{Cx}=$ Sample concentration; As = Standard peak area; $\mathrm{Ax}=$ Sample peak area; and $\mathrm{Cs}=$ Standard concentration $(0.09 \mu \mathrm{g} / \mathrm{g})$.

\subsection{DPPH Free Radical Scavenging Potential}

The antioxidant activity of the A. nitida extracts was determined by the Brand William method [18]. To prepare the standard solution of DPPH (2,2-D-phenyl-1-picrylhydrazyl), about $2 \mathrm{mg}$ of DPPH were dissolved in $100 \mathrm{~mL}$ of methanol. The solutions of various part (seeds, leaves, stem bark, and roots) extracts with concentrations in the range of $1 \mathrm{mg} / \mathrm{mL}$ were prepared in methanol and then diluted to concentrations of 1000, 500, 250, 125 and $62.5 \mu \mathrm{g} / \mathrm{mL}$. Approximately $0.1 \mathrm{~mL}$ of diluted solution of each plant part was mixed with $2 \mathrm{~mL}$ of DPPH solution in methanol and incubated for $30 \mathrm{~min}$ at $25^{\circ} \mathrm{C}$, finally the absorbance was measured at $517 \mathrm{~nm}$. Ascorbic acid was used as positive control. The experiments were performed in triplicate and the data obtained were presented as the mean \pm SEM. The percentage of free radical scavenging activity was calculated using the following equation:

$$
\text { Percent scavenging activity }=\frac{\text { Contol Abs }- \text { sample Abs }}{\text { control Abs }} \times 100
$$

\subsection{ABTS Free Radical Scavenging Potential}

According to the standard method [19], the relationship between the antioxidant potential of each part of $A$. nitida extract and the free radical ABTS (2,2-azinylbis [3ethylbenzothiazoline] 6-sulfonic acid) was evaluated. The stock solution $(1 \mathrm{mg} / \mathrm{mL})$ of plant extracts in methanol was prepared and then diluted to concentrations of 1000, 500, 250,125 and $62.5 \mu \mathrm{g} / \mathrm{mL}$. ABTS $(7 \mathrm{mM})$ and potassium persulfate $(2.45 \mathrm{mM})$ solution are mixed well and was kept in the dark overnight. After that mix $300 \mu \mathrm{L}$ of the test sample with $2 \mathrm{~mL}$ of ABTS solution, and then the absorbance was measured with a double-beam spectrophotometer. Ascorbic acid was used as a positive control. The results were recorded in triplicate and the percentage of ABTS free radical scavenging activity was calculated using Equation (2).

\subsection{Statistical Analysis}

Two-way analysis of variance (ANOVA) followed by Bonferroni poet-test was used for statistical analysis using Graph Pad Prism 5 version 5.01 software to determine the 
$p$ value. When $p \leq 0.05$, the difference is considered statistically significant. All tests are repeated in triplicate and the value is expressed as the Mean \pm SEM. Linear regression was used to calculate the $\mathrm{IC}_{50}$ value from the percentage inhibition of DPPH and ABTS of the plant extract samples at different concentrations, while Pearson's correlation coefficient $\left(\mathrm{R}^{2}\right)$ was used to determine the correlation of TPC and TFC vs. antioxidant activity (against DPPG and ABTS) of plant extracts using Excel 2007.

\section{Results}

\subsection{Total Phenolic and Flavonoid Contents}

The TPC and TFC in the Met. Ext of various parts of A. nitida are presented in Table 1. The highest phenolic contents were observed in the root sample ( $43.81 \mathrm{mg}$ GAE/g), followed by the leaf sample ( $43.77 \mathrm{mg} \mathrm{GAE} / \mathrm{g}$ ), with little differences. The stem bark (42.63 mg GAE/g) was ranked third in this category, while the lowest contents were recorded for the seed sample (40.57 $\mathrm{mg} \mathrm{GAE} / \mathrm{g})$.

Table 1. Total phenolic content and total flavonoid contents in various parts of A. nitida.

\begin{tabular}{cccc}
\hline S.NO. & Alnus nitida Part Used & $\begin{array}{c}\text { TPC (mg GAE/g of Dry } \\
\text { wt of the Extract) }\end{array}$ & $\begin{array}{c}\text { TFC (mg QE/g of Dry wt } \\
\text { of the Extract) }\end{array}$ \\
\hline 1 & Met. Ext Leaves & $43.77 \pm 1.07$ & $53.25 \pm 1.01$ \\
\hline 2 & Met. Ext Stem bark & $42.63 \pm 1.02$ & $45.55 \pm 1.03$ \\
\hline 3 & Met. Ext Seeds & $40.57 \pm 1.09$ & $43.54 \pm 1.04$ \\
\hline 4 & Met. Ext Root & $43.81 \pm 1.03$ & $51.33 \pm 1.06$ \\
\hline
\end{tabular}

TPC: total phenol content; TFC: total flavonoid content; Met. Ext: methanolic extract; GAE: gallic acid equivalents QE: quercetin equivalents; wt: weight.

The highest flavonoid contents were observed in the leaves $(53.25 \mathrm{mg} \mathrm{QE} / \mathrm{g})$ and root (51.33 mg QE/g) extracts of $A$. nitida, followed by stem bark (45.55 mg QE/g), and it was lowest in the seed sample (43.54 mg QE/g). Comparatively, the leaves sample had the highest TPC and TFC values (Table 1).

\subsection{DPPH Free Radical Scavenging Activity of A. nitida Methanolic Extracts}

Percent DPPH scavenging activity of various parts of $A$. nitida Met. Ext are presented in Table 2. The DPPH scavenging potential were in the order of leaves $(59.11 \pm 1.32)>$ stem bark $(56.14 \pm 0.45)>$ seeds $(51.24 \pm 1.38)>$ roots $(49.20 \pm 1.41)$ at highest concentration $1000 \mu \mathrm{g} / \mathrm{mL}$ with $\mathrm{IC}_{50}$ values of $340,740,800$, and $900 \mu \mathrm{g} / \mathrm{mL}$, respectively. The \%DPPH inhibition potential of Met. Ext dilutions were compared with ascorbic acid, which is used as the standard and has shown a concentration-dependent response. Ascorbic acid showed $79.32 \pm 0.61$ inhibition potential at high concentration $1000 \mu \mathrm{g} / \mathrm{mL}$ with $\mathrm{IC}_{50}$ value of $60 \mu \mathrm{g} / \mathrm{mL}$. The test samples also showed a concentration-dependent response.

\subsection{ABTS Free Radical Scavenging Activity of A. nitida Methanolic Extracts}

Percent ABTS scavenging activity of $A$. nitida Met. Ext of stem bark, leaves, seeds, and roots were noted as $55.16 \pm 0.09,51.20 \pm 1.10,48.16 \pm 0.10$, and $46.32 \pm 1.16$, respectively, at the highest concentration $1000 \mu \mathrm{g} / \mathrm{mL}$, whereas for ascorbic acid, the inhibition potential observed was $88.38 \pm 0.51$ at the mentioned highest concentration (Table 2). The calculated $\mathrm{IC}_{50}$ values of Met. Ext of stem bark, leaves, seeds, and roots were 645, 845, 960, and $1000 \mu \mathrm{g} / \mathrm{mL}$, respectively, whereas for ascorbic acid, this value was $60 \mu \mathrm{g} / \mathrm{mL}$.

\subsection{The Correlation of Total Phenolic/Flavonoid Contents versus Antioxidant Activity}

A linear correlation between total phenolic and flavonoid contents and antioxidant capacity were established, as shown in Figures 2 and 3. The highest regression values of TPC vs. antioxidant activity for the leaves extract was recorded $\left(\mathrm{DPPH}, \mathrm{R}^{2}=0.9934\right.$; $\mathrm{ABTS}$, $\left.R^{2}=0.9569\right)$, followed by stem bark (DPPH, $R^{2}=0.909$; ABTS, $\left.R^{2}=0.9667\right)$, and seed 
sample (DPPH, $\left.R^{2}=0.8902 ; A B T S, R^{2}=0.997\right)$, whereas for root, the values recorded were $\mathrm{DPPH}, \mathrm{R}^{2}=0.9814$ and ABTS, $\mathrm{R}^{2}=0.9869$.

Table 2. Percent DPPH and ABTS free radical screening activity of $A$. nitida methanolic extracts at various concentrations.

\begin{tabular}{|c|c|c|c|c|c|}
\hline Plant Extract & $\begin{array}{c}\text { Concentration } \\
(\mu \mathrm{g} / \mathrm{mL})\end{array}$ & $\begin{array}{c}\text { \%DPPH Scavenging } \\
\text { Mean } \pm \text { S.E.M }\end{array}$ & $\mathrm{IC}_{50}(\mu \mathrm{g} / \mathrm{mL})$ & $\begin{array}{c}\text { \%ABTS Scavenging } \\
\text { Mean } \pm \text { S.E.M }\end{array}$ & $\mathrm{IC}_{50}(\mu \mathrm{g} / \mathrm{mL})$ \\
\hline \multirow{5}{*}{ Met. Ext Leaves } & 1000 & $59.11 \pm 1.32 * *$ & \multirow{5}{*}{340} & $55.16 \pm 0.09 * *$ & \multirow{5}{*}{645} \\
\hline & 500 & $53.27 \pm 1.61^{* *}$ & & $47.20 \pm 0.04^{* * *}$ & \\
\hline & 250 & $47.18 \pm 0.42^{* * *}$ & & $41.18 \pm 0.01^{* * *}$ & \\
\hline & 125 & $38.27 \pm 0.93^{* * *}$ & & $38.28 \pm 1.16^{* * *}$ & \\
\hline & 62.5 & $31.30 \pm 0.50^{* * *}$ & & $32.16 \pm 1.10^{* * *}$ & \\
\hline \multirow{5}{*}{$\begin{array}{l}\text { Met. Ext Stem } \\
\text { Bark }\end{array}$} & 1000 & $56.14 \pm 0.45^{* *}$ & \multirow{5}{*}{740} & $51.20 \pm 1.10^{* *}$ & \multirow{5}{*}{845} \\
\hline & 500 & $43.15 \pm 0.55^{* * *}$ & & $45.16 \pm 1.09$ *** & \\
\hline & 250 & $38.30 \pm 0.64^{* * *}$ & & $39.28 \pm 1.18^{* * *}$ & \\
\hline & 125 & $35.42 \pm 0.66^{* * *}$ & & $35.21 \pm 1.15^{* * *}$ & \\
\hline & 62.5 & $27.20 \pm 0.57^{* * *}$ & & $28.42 \pm 0.21^{* * *}$ & \\
\hline \multirow{5}{*}{ Met. Ext Seeds } & 1000 & $51.24 \pm 1.38^{* *}$ & \multirow{5}{*}{800} & $48.16 \pm 0.10^{* * *}$ & \multirow{5}{*}{960} \\
\hline & 500 & $48.11 \pm 1.48^{* * *}$ & & $44.35 \pm 0.18^{* * *}$ & \\
\hline & 250 & $41.17 \pm 1.48^{* * *}$ & & $37.32 \pm 1.19 * * *$ & \\
\hline & 125 & $39.50 \pm 0.76^{* * *}$ & & $29.34 \pm 1.18^{* * *}$ & \\
\hline & 62.5 & $31.20 \pm 0.41^{* * *}$ & & $26.35 \pm 1.18^{* * *}$ & \\
\hline \multirow{5}{*}{ Met. Ext Roots } & 1000 & $49.20 \pm 1.41^{* * *}$ & \multirow{5}{*}{900} & $46.32 \pm 1.16^{* * *}$ & \multirow{5}{*}{1000} \\
\hline & 500 & $44.12 \pm 1.47^{* * *}$ & & $38.23 \pm 1.16^{* * *}$ & \\
\hline & 250 & $38.24 \pm 1.38^{* * *}$ & & $35.51 \pm 1.41^{* * *}$ & \\
\hline & 125 & $29.23 \pm 1.39^{* * *}$ & & $28.23 \pm 1.13^{* * *}$ & \\
\hline & 62.5 & $22.07 \pm 1.29^{* * *}$ & & $23.16 \pm 1.09 * * *$ & \\
\hline \multirow{5}{*}{ Ascorbic acid } & 1000 & $79.32 \pm 0.61$ & \multirow{5}{*}{60} & $85.55 \pm 0.33$ & \multirow{5}{*}{60} \\
\hline & 500 & $77.30 \pm 0.53$ & & $70.56 \pm 0.51$ & \\
\hline & 250 & $65.70 \pm 0.65$ & & $64.51 \pm 0.41$ & \\
\hline & 125 & $58.25 \pm 0.68$ & & $59.52 \pm 0.33$ & \\
\hline & 62.5 & $51.98 \pm 0.26$ & & $53.46 \pm 0.21$ & \\
\hline
\end{tabular}

Data are expressed as mean $\pm \mathrm{SEM},{ }^{* *} p<0.01,{ }^{* * *} p<0.001$; comparison of $A$. nitida Met. Ext vs. positive control ascorbic acid.

Similarly, the regression value of TFC vs. \% DPPH and ABTS in A. nitida various parts were as follows: leaves (DPPH, $\mathrm{R}^{2}=0.9932$; ABTS, $\left.\mathrm{R}^{2}=0.9686\right)$, stem bark (DPPH, $R^{2}=0.979 ;$ ABTS, $\left.R^{2}=0.9929\right)$, seeds $\left(D P P H, R^{2}=0.9273 ; A B T S, R^{2}=0.9733\right)$, and roots $\left(\mathrm{DPPH}, \mathrm{R}^{2}=0\right.$. 9673; ABTS, $\left.\mathrm{R}^{2}=0.9323\right)$ (Figure 3). Strong correlations exist between $\%$ TPC and \%TFC of $A$. nitida Met. Ext vs. antioxidant potentials. From the results, it can be inferred that phenolics and flavonoids are responsible for the antioxidant activity of the selected plant.

\subsection{Characterization of Phenolic Compounds through HPLC Technique}

The typical HPLC chromatograms of various parts (leaves, stem barks, seeds, and roots) of $A$. nitida are presented in Figure 4A-D. A total of six possible phytochemicals, malic acid, chlorogenic acid, epigallocatechin gallate, quercetin, ellagic acid, and pyrogallol, were identified in the Met. Ext of A. nitida leaves (Figure 4A). Three phenolic compounds, epigallocatechin gallate, ellagic acid, and pyrogallol, were identified in the Met. Ext of stem bark (Figure 4B). In the Met. Ext of seed, a total of six phenolic compounds, malic acid, vitamin C, epigallocatechin gallate, quercetin, ellagic acid, and pyrogallol, were identified (Figure 4C), while five phenolic compounds (malic acid, epigallocatechin gallate, quercetin, and ellagic acid) were identified in the Met. Ext of root (Figure 4D). The concentration and various parameters of the identified phytochemicals are presented in Table 3. 
Correlation between TPC and Antioxidant Activity

(A)

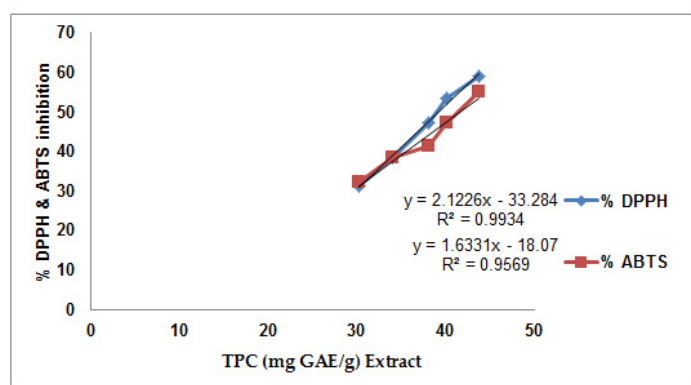

(C)

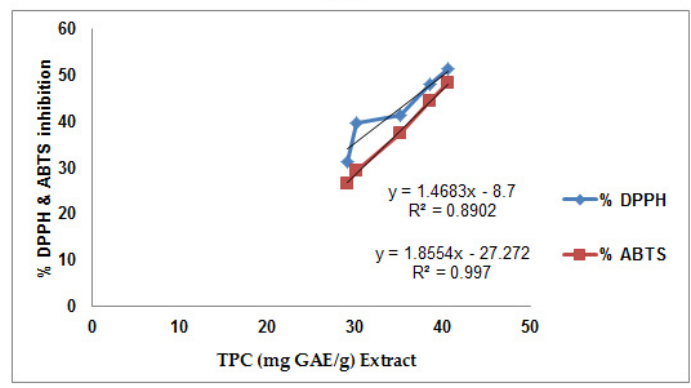

(B)

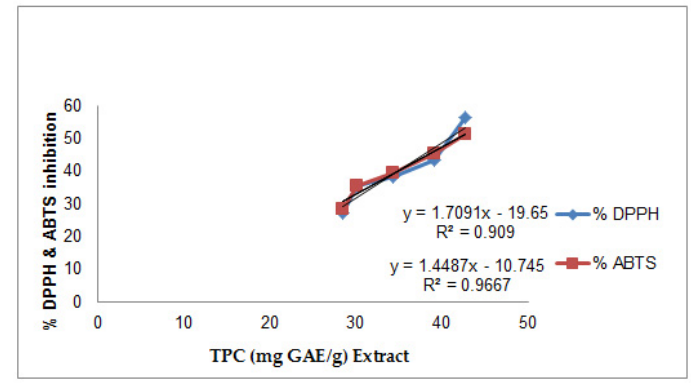

(D)

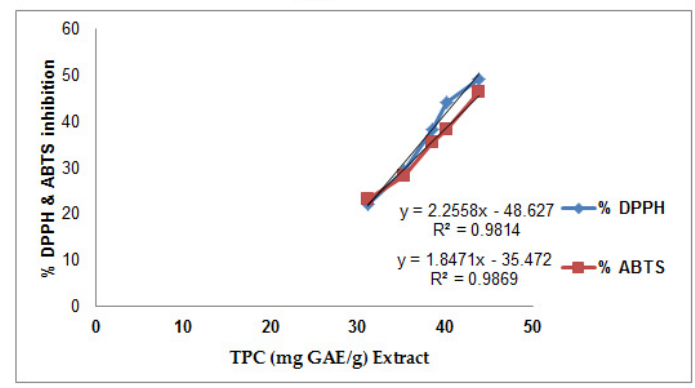

Figure 2. Correlation between total phenolic content in the methanolic extracts of $A$. nitida various parts (leaves, stem bark, seeds, and roots) versus percent antioxidant activity. The regression values are; (A) leaves (DPPH, $\mathrm{R}^{2}=0.9934 ; \mathrm{ABTS}$, $\left.R^{2}=0.9569\right)$, (B) stem bark (DPPH, $\left.R^{2}=0.909 ; A B T S, R^{2}=0.9667\right),(C)$ seeds $\left(D P P H, R^{2}=0.8902 ; A B T S, R^{2}=0.997\right)$, and (D) roots $\left(\mathrm{DPPH}, \mathrm{R}^{2}=0.9814 ; \mathrm{ABTS}, \mathrm{R}^{2}=0.9869\right)$.

Correlation between Total Flavonoid Contents and

(A)

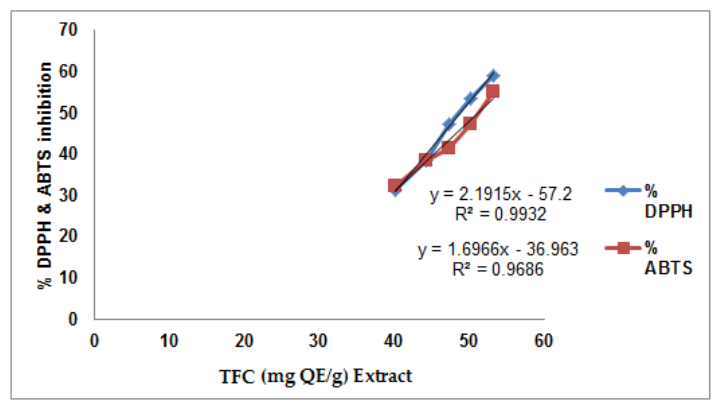

(C)

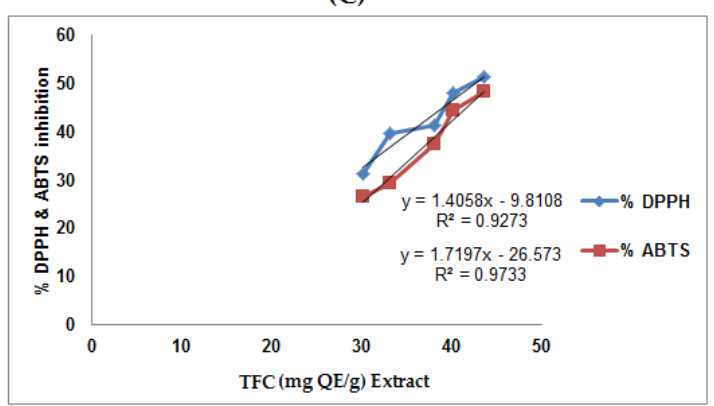

(B)

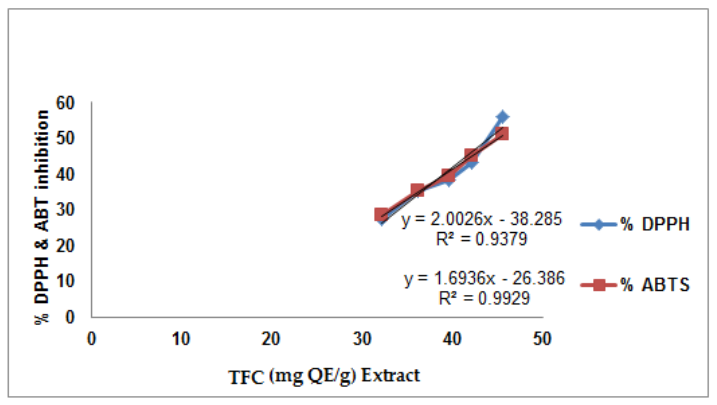

(D)

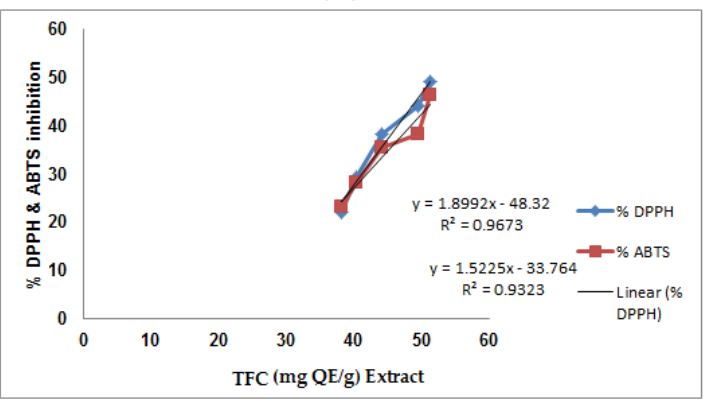

Figure 3. Correlation between total flavonoid in the methanolic extracts of $A$. nitida various parts (leaves, stem bark, seeds, and roots) content versus percent antioxidant activity. The regression values are; (A) leaves (DPPH, $\mathrm{R}^{2}=0.9932 ; \mathrm{ABTS}$, $\left.R^{2}=0.9686\right)$, (B) stem bark (DPPH, $\left.R^{2}=0.979 ; A B T S, R^{2}=0.9929\right),(C)$ seeds $\left(D P P H, R^{2}=0.9273 ; A B T S, R^{2}=0.9733\right)$, and (D) roots (DPPH, $\left.\mathrm{R}^{2}=0.9673 ; \mathrm{ABTS}, \mathrm{R}^{2}=0.9323\right)$. 
(A)

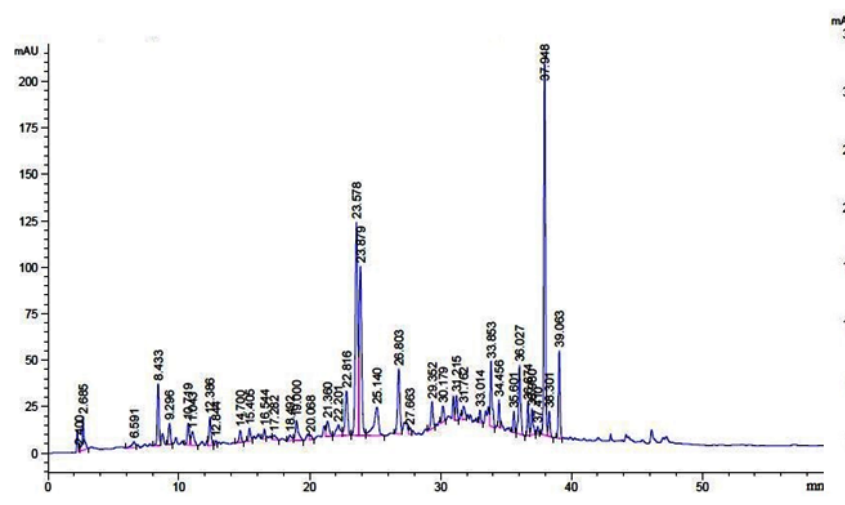

(C)

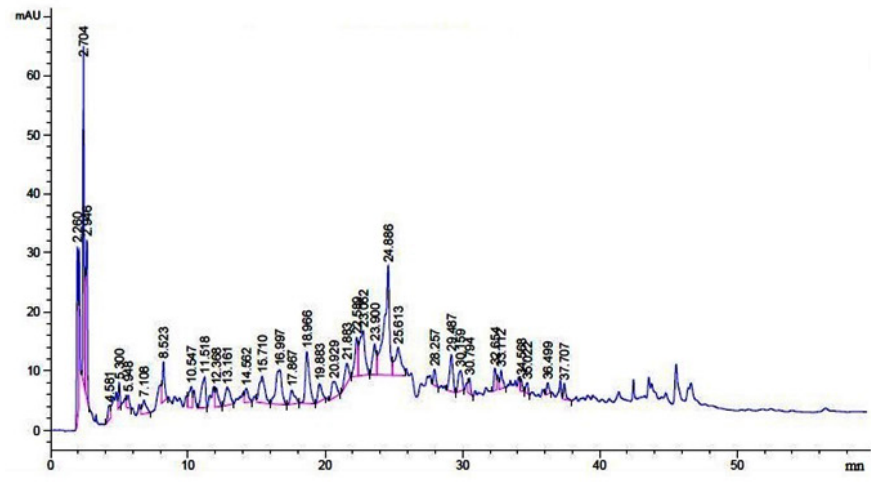

(B)

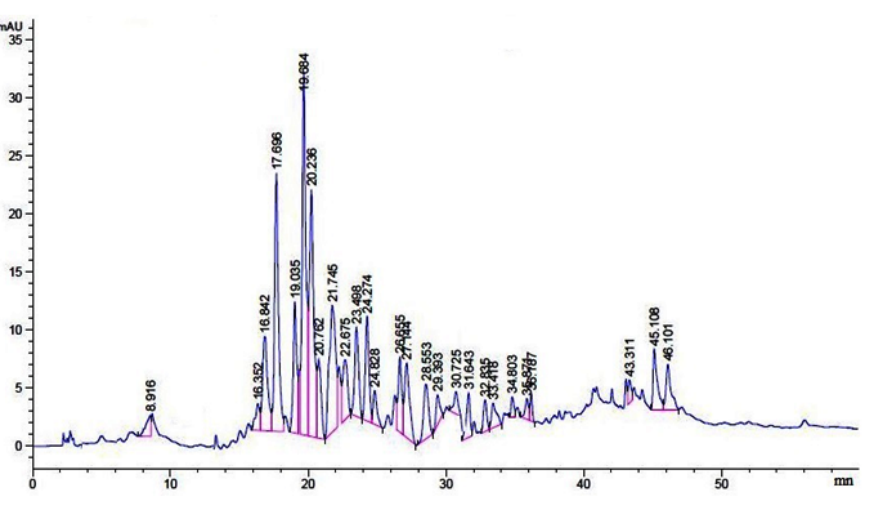

(D)

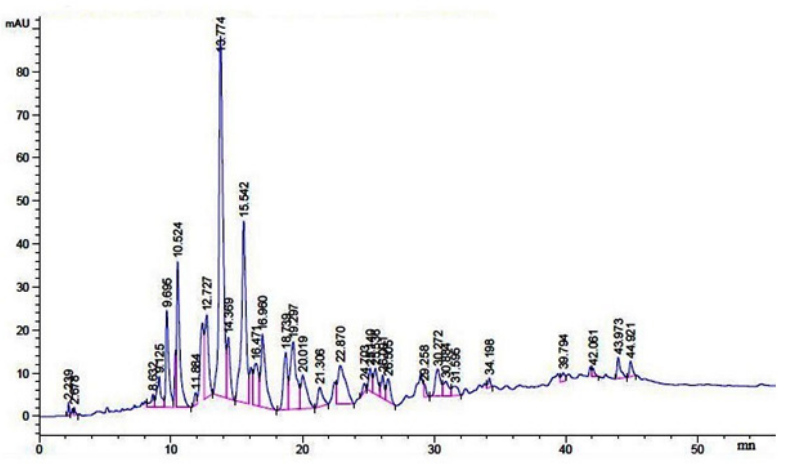

Figure 4. HPLC chromatograms of various parts of $A$. nitida: (A) leaves, (B) stem bark, (C) seeds, and (D) roots.

Table 3. Identification and Quantification of phenolic phytochemical compounds in Alnus nitida.

\begin{tabular}{ccccc}
\hline Part Used & No. of Peak & $\begin{array}{c}\text { Retention Time } \\
(\mathbf{m i n})\end{array}$ & Phenolic Compounds & $\begin{array}{c}\text { Concentration } \\
(\boldsymbol{\mu} \mathbf{g} / \mathbf{g})\end{array}$ \\
\hline \multirow{4}{*}{ Leaves } & 1 & 2 & Malic acid & 4.019 \\
& 2 & 6 & Chlorogenic acid & 12.535 \\
& 3 & 8 & Epigallocatechin gallate & 0.039 \\
& 4 & 10 & Quercetin & 0.016 \\
Stem bark & 5 & 16 & Ellagic acid & 0.142 \\
& 6 & 28 & Pyrogallol & 36.509 \\
& 1 & 8 & Epigallocatechin gallate & 0.006 \\
& 2 & 16 & Ellagic acid & 0.143 \\
Seeds & 3 & 28 & Pyrogallol & 104.405 \\
& 1 & 5 & Malic acid & 4.494 \\
& 2 & 8 & Vitamin C & 0.684 \\
& 3 & 10 & Quigallocitechin gallate & 0.009 \\
& 4 & 16 & Ellagic acid & 0.008 \\
Roots & 5 & 28 & Pyrogallol & 14.283 \\
& 6 & 2 & Malic acid & 3887.286 \\
& 1 & 8 & Epigallocatechin gallate & 0.284 \\
& 2 & 10 & Quercetin & 0.006 \\
& 3 & 16 & Ellagic acid & 0.069 \\
& 4 & & & 0.716 \\
\hline
\end{tabular}

\section{Discussion}

For thousands of years, nature has been a rich storage place for medicinal plants, and a large number of modern medicines have been isolated from natural sources, especially plant sources [20]. Plants are now considered to be an excellent source of antioxidant compounds (flavonoids, simple phenolics stilbene, anthocyanins), which are mainly used 
in the food industry as preservative to stop the deterioration of food. In the current study, the antioxidant potential of Alnus nitida stem bark, leaves, seed, and roots have been carried out along with HPLC profiling. Among phytochemicals, phenolic compounds and flavonoids are widely used as secondary metabolites of plants because it has shown antioxidant effects and are therefore very important. Many phenolic compounds are known to have effective anti-oxidant, anti-tumor, antibacterial, anti-viral or anti-inflammatory effects. Flavonoids are usually found in leaves, flower tissues, and pollen, are important antioxidants because they have been shown to be very effective scavengers for most types of oxidized molecules (including singlet oxygen and various free radicals) [21]. Results revealed that the leaves sample showed the highest TPC and TFC, whereas lowest values were recorded for seed extracts. Analysis showed that the Alnus nitida is a rich source of phytochemicals (phenolics and flavonoids), that is in step with the reported studies [13,22].

Antioxidants, especially phenols and flavonoids, have the ability to scavenge free radicals such as superoxide free radicals and hydroxyl free radicals due to the presence of benzene rings in their structures [23]. In order to study the complete antioxidant properties of A. nitida (bark, leaves, seeds and roots), two different in vitro assays (DPPH and ABTS, free radical scavengers) were used. The removal of DPPH and ABTS free radicals is considered a milestone in evaluating the antioxidant potential of plant extracts. It has been found that $A$. nitida leaf extract is a powerful free radical scavenger. Our results are consistent with those of Batool et al. [24] who found that the ethanolic extract of the Zanthoxylum alatum fruit is the most active radical scavenger. Published studies have also shown that the leaf, bark, and cone extracts from A. incana and A. viridis have a powerful ability to scavenge DPPH free radicals, which can be explained by their phytochemical composition [25], especially diarylheptanes and triterpenes [25]. According to the reported studies, ethanol extracts from stem bark of $A$. nitida and A. glutinosa can scavenge free radicals [13]. Our findings are also comparable to the results of Dahija et al. 2014 [22], who found a significant amount of total phenolic and flavonoid in leaves and bark extracts of the selected plants. Stević et al. [26] also reported the antioxidant effects of extracts from Alnus species.

Phenol and flavonoid molecules are important antioxidants, because it can donate hydrogen atoms to free radicals, and are responsible for deactivating free radicals. They also have ideal structural properties for scavenging free radicals. A correlation was made using Excel in order to establish the relationship among the total phenolic/flavonoid contents with antioxidant potentials determined through DPPH and ABTS assays, where high values of regression coefficient were recorded for TPC and TFC present in the Met. Ext of A. nitida various parts (leaves, stem bark, seeds, and roots) vs. antioxidant activity. A comparison of the regression values suggests that phenolic and flavonoid compounds are largely responsible for the antioxidant activity of the selected plant. Our results are in line with the reported study, where a significant positive correlation has been found between TPC and TFC with antioxidant activity [7].

In order to attribute the observed antioxidant activity to responsible possible phytochemicals, an HPLC analysis of the extracts was carried out and six phytochemicals (malic acid, chlorogenic acid, epigallocatechin gallate, quercetin, ellagic acid, and pyrogallol) were identified in the leaves extract of Alnus nitida, three phenolic compounds (epigallocatechin gallate, ellagic acid, and pyrogallol) were identified in the stem bark. A total of six phenolic compounds, malic acid, vitamin C, epigallocatechin gallate, quercetin, ellagic acid, and pyrogallol were identified in the seed, while four phenolic compounds, malic acid, epigallocatechin gallate, quercetin, and ellagic acid were identified in the root sample. Our results are fully consistent with published studies in which quercetin, morin and routine phytochemicals were identified in the methanolic extract of Silybum marianum (L.) seeds [27] and twelve phenolic compounds ( malic acid, gallic acid, vitamin C, chlorogenic acid, Epigallocatechin gallate, quercetin, morin, ellagic acid, catechin hydrate, rutin, pyrogallol, and mandelic acid) were found in the fruit of Elaeagnus umbellata Thunb. [14]. Malic acid, chlorogenic acid, quercetin, rutin, pyrogallol, mandelic acid, hydroxybenzoic 
acid and morin have been identified as potentially effective antioxidants in Rosa moschata methanolic extract [28]. Phenolic compounds were also found in two novel germplasm lines of Pisum sativum L., which showed higher antioxidant activity [29]. Therefore, it can be concluded that malic acid, chlorogenic acid, epigallocatechin gallate, quercetin, ellagic acid, and pyrogallol are the chief phenolic compounds that might be accountable for the observed antioxidant potential of the selected plant. In other studies, it has been reported that these compounds, chlorogenic acid [30], epigallocatechin gallate [31], quercetin [32], ellagic acid [33], pyrogallol [34] have potent antioxidant effects. A total of 273 compounds are reported from the seven Alnus species (A. japonica, A. hirsuta, A. glutinosa, A. incana, $A$. nepalensis, $A$. sieboldiana and $A$. firma), with very little or no attention being paid to alternative folks uses of those plants. The selected plant and other species of the same family needs more attention to be explored properly and in line with folkloric uses. A. nitida may be a favorable therapeutic candidate for the discovery of novel phytopharmaceuticals of industrial applications.

\section{Conclusions}

In the present study, the composition of the phytochemicals, the total content of phenols and flavonoids of the Met.Ext of various parts, leaves, stem bark, seeds, and roots of $A$. nitida were examined. The antioxidant activity of different parts of $A$. nitida Met.Ext against free radicals DPPH and ABTS was evaluated. The results showed that leaf extract is a good antioxidant agent because it has a stronger inhibitory effect on DPPH and ABTS free radicals, with $\mathrm{IC}_{50}$ values of 340 and $645 \mu \mathrm{g} / \mathrm{mL}$, respectively. It can be assumed that the difference in the antioxidant activity of different parts of $A$. nitida (leaves, stem bark, seeds and roots) could be due to differences in the concentration of the identified phenolic compounds present and might also be due to the higher levels of phenolics and flavonoids contents in the extract of selected samples.

The current results revealed that the plant is a prolific source of medicinally important phytoconstituents such as malic acid, chlorogenic acid, epigallocatechin gallate, quercetin, and pyrogallol, and the observed antioxidant potential might be due to these constituents. Although the parameters used in this study are not disease-specific, the quantification of their antioxidant properties can be used to guide the application of these plants in ROS-related complications, including diabetes. More research is needed to isolate and identify the responsible antioxidants and their mechanisms of action in order to better understand their potency to control relevant diseases.

Author Contributions: Writing original draft preparation, J.K. and N.N.; Supervision, A.M. and M.N.; Formal analysis, A.A.K.K.; Conceptualization and revisions, M.Z.; Data curation and proof reading, R.U. and A.B.S.; Validation, M.I.; Funding, A.B.; Formal analysis, A.B.S. All authors have read and agreed to the published version of the manuscript.

Funding: This research was funded by King Saud University Research Supporting Project Number: RSP-2021/346.

Institutional Review Board Statement: Not Applicable.

Informed Consent Statement: Not Applicable.

Data Availability Statement: The data presented in this manuscript belong to the Ph.D. research work of Javed Khan. No data in any repository available and has been totally represented in this paper.

Acknowledgments: Authors wish to thanks Research Supporting Project Number: RSP-2021/346 King Saud University Riyadh Saudi Arabia for their financial support.

Conflicts of Interest: The authors declare no conflict of interest. 


$\begin{array}{ll}\text { Abbreviations } \\ \text { A. nitida } & \text { Alnus nitida } \\ \text { HPLC } & \text { High-performance liquid chromatography } \\ \text { DPPH } & \text { 2,2-diphenyl-1-picrylhydrazyl } \\ \text { ABTS } & \text { 2,2-azinobis [3-ethylbenzthiazoline]-6-sulfonic acid } \\ \text { IC } 50 & \text { Half maximal inhibitory concentration } \\ \text { B.G.H } & \text { Botanical Garden Herbarium } \\ \text { TPC } & \text { Total phenolic content } \\ \text { TFC } & \text { Total flavonoid content } \\ \text { DAD } & \text { Diode array detector } \\ \text { UVAD } & \text { Ultraviolet array detector } \\ \text { ANOVA } & \text { Analysis of variance }\end{array}$

\section{References}

1. Bhukta, A. Traditional Knowledge: An Overview. Legal Protection for Knowledge; Emerald Publishing Limited: Bingley, UK, 2020.

2. Maxted, N.; Brehm, J.M. Key steps in conservation and use of plant genetic resources: An overview. Plant. Genet. Resour. 2021, 15, 103-137.

3. Tiwari, P.; Khare, T.; Shriram, V.; Bae, H.; Kumar, V. Plant synthetic biology for producing potent phyto-antimicrobials to combat antimicrobial resistance. Biotechnol. Adv. 2021, 48, 107729. [CrossRef]

4. Maliński, M.P.; Kikowska, M.A.; Soluch, A.; Kowalczyk, M.; Stochmal, A.; Thiem, B. Phytochemical screening, phenolic compounds and antioxidant activity of biomass from Lychnis flos-cuculi L. In vitro cultures and intact plants. Plants 2021, 10, 206. [CrossRef]

5. Sajid, M.; Khan, M.R.; Shah, S.A.; Majid, M.; Ismail, H.; Maryam, S.; Batool, R.; Younis, T. Investigations on anti-inflammatory and analgesic activities of Alnus nitida spach (Endl.) stem bark in sprague dawley rats. J. Ethnopharmacol. 2017, 198, 407-416. [CrossRef]

6. Shaukat, U.; Ahemad, S.; Wang, M.; Khan, S.I.; Ali, Z.; Tousif, M.I.; Abdallah, H.H.; Khan, I.A.; Saleem, M.; Mahomoodally, M.F. Phenolic contents, chemical profiling, in silico and in vitro anti-inflammatory and anticancer properties of Alnus nitida (spach) Endl. S. Afr. J. Bot. 2021, 138, 148-155. [CrossRef]

7. Sajid, M.; Khan, M.R.; Shah, N.A.; Shah, S.A.; Ismail, H.; Younis, T.; Zahra, Z. Phytochemical, antioxidant and hepatoprotective effects of Alnus nitida bark in carbon tetrachloride challenged sprague dawley rats. BMC Complement. Altern. Med. 2016, 16, 1-17. [CrossRef]

8. Haq, Z.; Khan, S.; Ahmad, Z.; Shah, S.; Mustafa, G.; Razzaq, A.; Manan, F.; Ullah, A.; Hussai, M. An evaluation of conservation status and ecological zonation of Alnus nitida; a monophyletic species of the sino-Japanese region. J. Anim. Plant. Sci. 2020, 30, $1224-1235$.

9. Uddina, G.; Raufa, A.; Bibib, S.; Khanc, H.; Haddad, T.B.; Ramadan, M.F. Bioactive compounds and biological activities of Alnus nitida. Alles Nur Kopiert Und Geklaut? 2017, 1, 121.

10. Sati, S.C.; Sati, N.; Sati, O. Bioactive constituents and medicinal importance of genus alnus. Pharmacogn. Rev. 2011, 5, 174. [CrossRef]

11. Mingarro, D.M.; Acero, N. Methanolic Alnus glutinosa bark extract affect ROS and TNF- $\alpha$ production. Planta Med. 2011, 77, PM165. [CrossRef]

12. León-Gonzalez, A.; Acero, N.; Muñoz-Mingarro, D.; López-Lázaro, M.; Martín-Cordero, C. Cytotoxic activity of hirsutanone, a diarylheptanoid isolated from Alnus glutinosa leaves. Phytomedicine 2014, 21, 866-870. [CrossRef]

13. Sajid, M.; Yan, C.; Li, D.; Merugu, S.B.; Negi, H.; Khan, M.R. Potent anti-cancer activity of Alnus nitida against lung cancer cells; in vitro and in vivo studies. Biomed. Pharmacother. 2019, 110, 254-264. [CrossRef]

14. Nazir, N.; Zahoor, M.; Nisar, M.; Khan, I.; Karim, N.; Abdel-Halim, H.; Ali, A. Phytochemical analysis and antidiabetic potential of Elaeagnus umbellata (Thunb.) in streptozotocin-induced diabetic rats: Pharmacological and computational approach. BMC Complement. Altern. Med. 2018, 18, 332. [CrossRef]

15. Shirazi, O.U.; Khattak, M.; Shukri, N.A.M.; Nasyriq, M.N. Determination of total phenolic, flavonoid content and free radical scavenging activities of common herbs and spices. J. Pharmacogn. Phytochem. 2014, 3, 104-108.

16. Kim, D.O.; Jeong, S.W.; Lee, C.Y. Antioxidant capacity of phenolic phytochemicals from various cultivars of plums. Food Chem. 2003, 81, 321-326. [CrossRef]

17. Alam, Z. A reversed phase HPLC-DAD method for the determination of phenolic compounds in plant leaves. Anal. Methods. 2015, 7, 7753-7757.

18. Brand-Williams, W.; Cuvelier, M.; Berset, C. Use of a free radical method to evaluate antioxidant activity. LWT Food Sci. Technol. 1995, 28, 25-30. [CrossRef]

19. Re, R.; Pellegrini, N.; Proteggente, A.; Pannala, A.; Re, Y.M. Antioxidant activity applying an improved FBTS radical cation decolorization assay. Free Rad. Biol. Med. 1999, 26, 7-1231. [CrossRef] 
20. Afsar, T.; Trembley, J.H.; Salomon, C.E.; Razak, S.; Khan, M.R.; Ahmed, K. Growth inhibition and apoptosis in cancer cells induced by polyphenolic compounds of Acacia hydaspica: Involvement of multiple signal transduction pathways. Sci. Rep. 2016, 6, 23077. [CrossRef]

21. Moncayo, S.; Cornejo, X.; Castillo, J.; Valdez, V. Preliminary phytochemical screening for antioxidant activity and content of phenols and flavonoids of 18 species of plants native to western Ecuador. Trends Phytochem. Res. 2021, 5, 93-104.

22. Dahija, S.; Čakar, J.; Vidic, D.; Maksimović, M.; Parić, A. Total phenolic and flavonoid contents, antioxidant and antimicrobial activities of Alnus glutinosa (L.) Gaertn., Alnus incana (L.) moench and Alnus viridis (chaix) dc. extracts. Nat. Prod. Res. 2014, 28, 2317-2320. [CrossRef]

23. Njoya, E.M. Chapter 31-Medicinal Plants, Antioxidant Potential, and Cancer; Academic Press: San Diego, CA, USA, 2021; pp. 349-357.

24. Batool, F.; Sabir, S.M.; Rocha, J.; Shah, A.H.; Saify, Z.S.; Ahmed, S.D. Evaluation of antioxidant and free radical scavenging activities of fruit extract from Zanthoxylum alatum: A commonly used spice from Pakistan. Pak. J. Bot. 2010, 42, 4299-4311.

25. Ren, X.; He, T.; Chang, Y.; Zhao, Y.; Chen, X.; Bai, S.; Wang, L.; Shen, M.; She, G. The Genus alnus, a comprehensive outline of its chemical constituents and biological activities. Molecules 2017, 22, 1383. [CrossRef] [PubMed]

26. Stević, T.; Šavikin, K.; Zdunić, G.; Stanojković, T.; Juranić, Z.; Janković, T.; Menković, N. Antioxidant, cytotoxic, and antimicrobial activity of Alnus incana (L.) ssp. incana moench and A. viridis (chaix) dc ssp. viridis extracts. J. Med. Food. 2010, 13, 700-704. [CrossRef] [PubMed]

27. Nazir, N.; Karim, N.; Abdel-Halim, H.; Khan, I.; Wadood, S.F.; Nisar, M. Phytochemical analysis, molecular docking and antiamnesic effects of methanolic extract of Silybum marianum (L.) gaertn seeds in scopolamine induced memory impairment in mice. J. Ethnopharmacol. 2018, 210, 198-208. [CrossRef]

28. Nazir, N.; Khalil, A.A.K.; Nisar, M.; Zahoor, M.; Ahmad, S. HPLC-UV characterization, anticholinesterase, and free radicalscavenging activities of rosa moschata herrm. leaves and fruits methanolic extracts. Braz. J. Bot. 2020, 43, 523-530. [CrossRef]

29. Nazir, N.; Nisar, M.; Ahmad, S.; Wadood, S.; Jan, T.; Zahoor, M.; Ahmad, M.; Ullah, A. Characterization of phenolic compounds in two novel lines of Pisum sativum L. along with their in vitro antioxidant potential. Environ. Sci. Pollut. Res. 2019, 27, 7639-7646. [CrossRef]

30. Gökbulut, A.; Yazgan, A.N.; Duman, H.; Yilmaz, B.S. Evaluation of the antioxidant potential and chlorogenic acid contents of three endemic sideritis taxa from Turkey. J. Pharm. Sci. 2017, 42, 81.

31. Moreno-Vásquez, M.J.; Plascencia-Jatomea, M.; Sánchez-Valdes, S.; Tanori-Córdova, J.C.; Castillo-Yañez, F.J.; Quintero-Reyes, I.E.; Graciano-Verdugo, A.Z. Characterization of epigallocatechin-gallate-grafted chitosan nanoparticles and evaluation of their antibacterial and antioxidant potential. Polymers 2021, 13, 1375. [CrossRef] [PubMed]

32. Halevas, E.; Mavroidi, B.; Pelecanou, M.; Hatzidimitriou, A.G. Structurally characterized zinc complexes of flavonoids chrysin and quercetin with antioxidant potential. Inorg. Chim. Acta. 2021, 523, 120407. [CrossRef]

33. Karakurt, S.; Semiz, A.; Celik, G.; Gencler-Ozkan, A.M.; Sen, A.; Adali, O. Contribution of ellagic acid on the antioxidant potential of medicinal plant Epilobium hirsutum. Nutr. Cancer. 2016, 68, 173-183. [CrossRef] [PubMed]

34. Sutanto, H.; Susanto, B.H.; Nasikin, M. Solubility and antioxidant potential of a pyrogallol derivative for biodiesel additive. Molecules 2019, 24, 2439. [CrossRef] [PubMed] 